\title{
Death-Related and Mystical Visions Relevant to Consciousness Studies
}

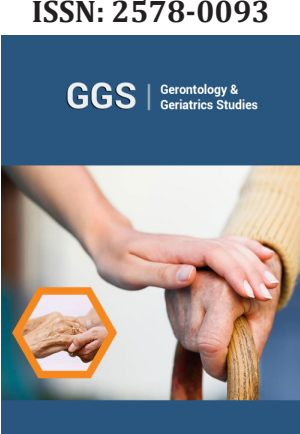

*Corresponding author: Dr James Paul Pandarakalam, Department of Psychiatry, Hollins Park Hospital, Warrington, UK.

"Old age comes from Him,

Old age leads to Him,

Old age will touch me,

Only in so far as He wills."

(Hymn of the Universe, Teilhard de Chardin)

Submission: 眥 November 11, 2019

Published: 此 November 25, 2019

Volume 5 - Issue 3

How to cite this article: James Paul Pandarakalam. Death-Related and Mystical Visions Relevant to Consciousness Studies. Gerontol \& Geriatric stud.5(3). GGS.000614.2019.

DOI: $10.31031 /$ GGS.2019.05.000614

Copyright@ James Paul Pandarakalam This article is distributed under the terms of the Creative Commons Attribution 4.0 International License, which permits unrestricted use and redistribution provided that the original author and source are credited.

\author{
James Paul Pandarakalam*
}

Department of Psychiatry, Hollins Park Hospital, Warrington, UK

\begin{abstract}
Paranormal and mystical experiences challenge reductionism and ultra-reductionism-the assumption that the whole is the same as the sum of its parts. Quantum is the bedrock of matter, but mysticism is the bedrock of reality. In this respect, studies of mysticism are an unavoidable part of a scientific quest. The study of near-death experiences (NDEs) has brought the exploration of post-mortem existence to the scientific arena. Similarly, studies of Marian apparitions could be bringing mysticism to the realm of the scientific imagination. From a spiritual and scientific perspective, the ongoing Marian apparitional occurrences in Medjugorje (Bosnia) are highly valuable. Ultra-reductionism is a serious challenge, and this can be addressed by exploring mysticism. Self-realization, discarnate existence, and God realization are important aspects of spirituality. Death-related visions offer evidence of an extended consciousness and its survival after physical extinction, but additionally, Marian mysticism illuminates us of the Heavenly realities and contributes meaning to terrestrial existence. In view of the accumulating evidence in favor of the reality of discarnate existence, the medical viewpoint toward assisted suicide needs to be morally evaluated. Terminal illness and the final years of life become transitional preparatory periods, whereby we disengage with the pleasant and unpleasant illusions of earthly existence, which could turn out to be spiritually productive.
\end{abstract}

Keywords: Near-death experiences; Pre-death visions; Mysticism; Marian apparitions; Discarnate existence

\section{Introduction}

Many recent studies on consciousness apparently represent a departure from the beaten track of reductionist materialism. Mystical experiences tell us more about the founding principles of reality. Many contemporary scientists portray mystical experiences as subjective illusions or mirages. Brain changes may be intrinsic to mystical experiences, but this is not evidence that the brain generates them. Computational theories or bio-physicist theories of the mind and consciousness cannot explain mystical experiences and creativity of a higher order. Subjective human attributes, such as unconditional love, empathy, and compassion, are reflections of a higher/spiritual dimension. Scientifically investigated Marian apparitions at Medjugorje (Bosnia, 1981 to date) would potentially challenge the skepticism of mainstream scientists regarding paranormal phenomena. A theory of mind and consciousness based on mystical experiences, particle physics, and neurosciences can be more accurate than one that excludes mystical experience. Raymond Moody's studies of near-death experiences (NDEs) constitute a benchmark in survival research $[1,2]$. NDE studies corroborate a host of deathrelated phenomena, including pre-death visions and shared-death experiences (SDEs). Accordingly, NDEs merit recognition as part of the spectrum of spiritual events that relate to the dying and their families [3]. All three of the aforementioned groups of death-related studies are interlinked, and they feature parallel characteristics. Common themes among the groups are otherworldly realms and encounters with a being of light and meeting deceased relatives or friends. Marian apparitional experiences also provide insights into unfamiliar otherworldly realms, angelic spirits, and negative entities-as well as the whereabouts of deceased relatives.

The observations of the percipients of twentieth and twenty-first century Marian apparitions provide some validation from an external source of various otherworldly elements of NDEs [4,5]. NDEs, pre-death visions, and SDEs inform us about post-mortem existence without clearly distinguishing the disparate forms of discarnate life. Whereas Marian apparitions not only authenticate the continuity of life after death; they also bring into focus well-defined forms of discarnate life, thereby highlighting the sanctity of terrestrial 
existence. In this respect, the manifestations of Medjugorje, Kibeho, and Fatima are particularly enlightening.

\section{Near Death Experiences}

Over the years, various explanations have been put forward for the widely recognized variety of NDEs. Early investigators attached disproportionate significance to the transcendental aspects of these kinds of experiences, and those views were challenged by biological explanations. Both biological and transcendental interpretations have obvious inherent pitfalls. An intermediate position is the most preferred view: that NDEs are a combination of individual hallucinations and true extra sensory perception. The current models of the mind are inadequate to explain NDEs, and a study of NDEs facilitates attempts to gain a deeper understanding of the mind. NDEs may be explained by the putative existence of an extra cerebral component in association with the brain, even though this unphysical part is unobservable using present-day instrumentation.

NDEs typically involve a feeling of deep peace, followed by a sensation of floating up through a tunnel toward a bright light. However, some varieties of the experience are far from euphoricspecifically, the cognitive, affective, and transcendental ones. Cognitive features include distortions of time and a review of one's life or a panoramic memory; affective ones are feelings of peace or joy. Visual images of a heavenly world and deceased relatives are common transcendental features. Other commonly reported elements include buzzing or rushing sounds, a feeling of separation from the body, extra-somatic experiences, out-of-body experiences (OBEs), passing through a void or tunnel, experiencing a bright spiritual light, and encountering a border or a limit. There are documented instances of OBEs that involve externally verifiable information [6]. Many people encounter only fragments of the experience. A quarter of NDEs are negative, and those who are subjected to this kind also sometimes report OBEs and a dark transition zone, the latter sensed while enduring unpleasant feelings of fear or even panic. Subsequently, the subjects encounter bad forces or beings and enter a hellish environment. Negative NDEs do sometimes have a positive life-changing effect, though they are more prone to being suppressed than positive NDEs. NDE narrations propose that the level of the dimension in which the subject travels is dependent upon the energy levels and frequencies of light in the spiritual body of the individual. It is posited that these, in turn, are based on human behavior while on earth, and possibly also depend on the energy level and frequencies of light of the helpers who manifest as coming to assist the transition [7].

NDEs may be apportioned to major divisions, the most important of which is Cities of Light with their associated countryside. The second major division is the Realm of Bewildered Spirits. A third division, called Hell, is postulated by a few who have had NDEs. The Cities of Light are built of crystal, feature cool light, and appear at different levels, with each city grander than the last one and all characterized by an intense level of activity. The Cities are surrounded by countryside with beautiful landscapes of mountains, hills, and valleys, all embellished by fields of golden grass and flowers, meadows, paths, trails, lanes, roads, great forests, brooks, streams, rivers, ponds, and lakes, all of which are typical features of life on Earth [8]. The Realm of Bewildered Spirits is described as a dark, gloomy, and hostile environment, peopled by millions of unhappy and wicked people who are grey, bewildered, confused, miserable, anguished, dreary, angry, and uncommunicative, and preoccupied with unresolved problems [8]. The distinction between the second division and the third is not always clear.

NDEs offer a model of spiritual visions combined with introvertive apparitions; it is clear that they happen when the brain is underactive, and no sensory visions are taking place. A person who has an NDE perceives their body from an external location and often is met by one or more spiritual beings who communicate with them. Many of the perceptual features of such events, which are experienced as real, are notoriously difficult to put into words. This is the noetic quality of mystical experience identified by William James. Ten thousand cases of NDEs have been well documented, far too many to dismiss or ignore. NDEs are a significant manifestation, and like jigsaw puzzles, their pieces have to be put together in order to comprehend them in their entirety. NDEs are heavily influenced by culture and belief systems. Christians see a Christian construct; the Hmong and Native Americans see ancestor-based constructs; and Hindus experience a strongly Hindu-based construct. A transcendental reality may be manifested in NDEs.

\section{Deathbed visions, SDEs}

Pre-death visions validate the paranormal components of NDEs and occur in full consciousness [9]. These phenomena include visions of dead friends and relatives, landscapes from beyond, and heightened sensations of elation or euphoria, all taking place in the period immediately preceding actual death. Some of the components of clinical death experiences are identical to deathbed visions occurring at the borders of life and cannot be easily explained in biological terms. While healthy persons report hallucinations centered on living individuals, dying people claim to have hallucinations of deceased persons. The perceptions of dying persons may be considered a defense mechanism to reduce death anxiety by imagining a reunion with familiar persons. This view is, however, challenged by cases in which a person who was near death reported seeing a recently deceased person about whom they had no explicable information about their death $[10,11]$. Pre-death visions may be true departing visions, whereas NDEs are perhaps only parting visions. Pre-death visions support a survival hypothesis but do not offer us any enlightenment about the different forms of discarnate existence.

SDEs are a new addition to survival research, even though Myers mentioned such experiences in his classic book on the survival problem. Among these experiences are awareness of persons present at the death of their loved one, accompanied by a feeling of leaving the body, experiencing a review of the lives of loved ones, and travelling partway toward the light. Such experiences, though common, have been rarely reported in the NDE literature. Raymond Moody distinguishes them as "empathic NDEs," "conjoint 
NDEs," or "mutual NDEs" [1]. Like deathbed visions, SDEs may contribute significantly to the evidence for discarnate survival. Peter and Elizabeth Fenwick reported a case in which a daughter, who was sitting beside her mother's deathbed, experienced a vision where she saw a beautiful garden and hillside. From this, she saw a deceased aunt holding out her hands to her dying mother. The mother and aunt met and went away together [12].

Moody et al. [2] recognizes seven elements in cases of SDEs [2]:

- $\quad$ change of geometry;

- $\quad$ mystical light;

- $\quad$ music and musical sounds;

- $\quad$ OBE;

- $\quad$ co-living a life review;

- $\quad$ encountering unworldly realms; and

- $\quad$ mist at death

These elements are not normally all present in the reported cases, and just a few of the seven may be present in individual cases. Moody has recounted his own SDE in 1994-along with the rest of his family-in relation to his mother [2]. Real SDEs cannot be explained away by biological interpretations of NDEs. Like pre-death visions, SDEs inform us that death is only the end of a biological chain of events-a comma and not a full stop and they do not inform us about the different forms of discarnate survival. In this respect, Marian mystical experiences are more enlightening.

\section{Mysticism}

Mystics have existed throughout the centuries, exploring the inner realms. They are like the Hubble Space Telescope, exploring the outer universe. Marian mysticism is not confined to any religion, and it is helpful in mapping out the after-death realms. Scientists who are trying to develop a deeper understanding of consciousness cannot shy away from such experiences. If science is the search for truth, spirituality is the search for meaning of existence, and both combined harmoniously can enrichen human lives. The parapsychological definition of mysticism is that any non-ordinary experience that gives a sense of the beyond is a mystical experience. In the Jungian model, introvertive visionary experiences involve the activation of the unconscious archetypal psyche, which then dominates consciousness. This is the part of the mind that produces dreams and myths. Theology broadly divides visions into the mystical and the prophetic and the former exclusively refer to a particular person and his personal spiritual growth. The prophetic visions have a public character right from the beginning. They are a gift or a charism to the individual or several individuals for the benefit of the whole humanity. The mystical vision is always more intense and more strongly influences visionary's personal life than is the case with the prophetic vision. Marian apparitions have the characteristics of both mystical and prophetic visions.

The anthropologist Anthony Wallace has documented several cases in which individuals underwent what seemed to be psychotic episodes and subsequently developed an entirely new mythology and way of life for their social group [13]. In clinical practice, the author has come across similar breakthrough experiences that are quite transformative. Introvertive visionary experiences, due to the activation of the psyche to an intense degree, may even present with beliefs that meet the criteria for delusions of the fourth edition of the Diagnostic and Statistical Manual of Mental Disorders (DSMIV), particularly grandiose ones accompanied by hallucinations. Mystical experiences may be broadly divided into spiritual visions and apparitional experiences of a transcendental nature that includes Marian apparitional experiences.

\section{Spiritual Visions}

Spiritual visions have personal psycho-spiritual contributions as well as contributions from external spiritual agencies. They can be divided into introvertive and extroversive visionary experiences. Introvertive visions appear to be fueled by the individual's own biopsychical abilities. The percipients tend to embellish the truth when communicating their experiences to other people. As introvertive spiritual experiences have a self-generated component, they may persist for a relatively long period. In technologically less-advanced cultures, transcendent or unseen order seems to manifest itselfoften in apparitions-through the performances of spirit mediums and shamans. Such perceptions are often pure psycho-spiritual experiences and may or may not contain transcendental elements. These spiritual visions are interpreted within a religious framework and are not a goal in themselves but part of a larger path of selftransformation. The concept of breakthrough experiences, not breakdown experiences, is gaining ground within the inner circles of psychiatry. Introvertive visions are a voluntary phenomenon. The percipients need to practice prayerfulness, meditation, contemplative exercises, and intense concentration techniques. Introvertive visions may have a dream-like quality and may take the form of mental images. The percipients experience reflections of transcendental realities that are purely of a subjective nature. There is a continuum between spiritual visions and creativity. The four stages of creativity, namely information processing and storage, incubation period, illumination, and elaboration, are not confined to scientific creativity alone. They occur in everyday life as well as in introvertive spiritual visions.

The quantum mind does the groundwork and the spiritual body (quantum-like consciousness) is the main participant of spiritual visions. I contend that the quantum mind is the mediator between the brain and spiritual consciousness. In extravertive spiritual, visions, the spiritual body communicates with the transcendental realities, quantum contributes the cultural construct in storage, and the whole exchange of information results in spiritual visions. The non-ordinary experience is characterized by a sense of unreality. Quantum is recognized as the dream machine, and spiritual visions become like a quantum/spiritual hologram. Those who can believe in the paranormal component of creativity [14] are in an advantageous position to develop an approximate model of introvertive spiritual visions, in which the brain bypasses the time lag for transmission of information from the spiritual plane to the 
physical brain. Like dreams, these categories of visions are knitted with symbols.

Spiritual visions are colored by cultural constructs, and this is more prominent in introvertive spiritual visions than in extroversive spiritual visions. The paranormal may be inserted into the cultural construct in instances of extravertive spiritual visions to the extent that it dominates the experience; in introvertive spiritual visions, the cultural construct dominates, and paranormal elements are implanted into it. In most cases, the two kinds interact in the same percipient to some extent. In this paper, I am compartmentalizing mystical experiences into four subcategories, viz,

1. Introvertive spiritual experiences,

2. Extroversive spiritual experiences,

3. Inward apparitional experiences,

4. Outward apparitional experiences (Table 1).

Table 1: Mystical experiences.

\begin{tabular}{|r|}
\hline A. Spiritual Visions \\
\hline 1.Self-generated introvertive spiritual visions-occurs in the mind's eyes \\
\hline 2.Extrovertive spiritual visions are also self-generated, but with the involvement of external agencies and without sensual experiences \\
\hline 1.Inward apparitions generated by external agencies without sensual experiences \\
\hline 2.Outward apparitions with external and internal perceptions-Outward cum inward apparitional experiences, generated by external agencies.
\end{tabular}

Spiritual visions without the mediation of physical senses may thus be divided into two types. A. Introvertive-These visions are an expression of self-generated and self-induced ecstasy. They may involve self-hypnosis, they may contain a paranormal element, and they need stringent discernment. They are akin to psycho-spiritual projections and are essentially pure subjective experiences. B. extravertive-These visions are also internally generated spiritual visions and contain one's own psychological constructs as well external contributions. Ecstasy is supposed to be generated by an outside agency. Hetero hypnosis occurs at a subjective and spiritual level. They contain paranormal elements and are subjectiveobjective experiences, again warranting scrupulous discernment. It is harder to identify and confirm the external agency in spiritual visions than it is to recognize the apparitional figure in an outward apparitional experience.

Stace Walter has used the terms "introvertive mysticism" and "extroversive mysticism" to distinguish the different forms of mystical events [15]. The word "mysticism" is sometimes misused and wrongly attributed to normal spiritual or paranormal phenomena. According to Carl Jung, mysteries magnum (the great mystery) is first and foremost rooted in human psychology, and spirituality and religion are secondary to that. In this paper, the word "spiritual" is used to refer to phenomena linked to the spiritual body that are not externalized sensual experiences. The percipients at Medjugorje apparitional occurrences (Bosnia) claim to be merely visionaries, although their extraordinary experiences have mystical qualities.

Here, I use the word "spiritual" not as a synonym for mystical phenomena, but to refer to phenomena in which the spiritual senses are directly involved and distinct from the quantum mind. (I have borrowed and modified the terms "introvertive" and "extravertive" in relation to spiritual visions from Stace Walter.) Such a claim requires a revision of our current models of the mind; we need to incorporate an extended consciousness or spiritual consciousness to the brain-mind-consciousness complex. Spiritual consciousness may be merely a property of a spiritual body formed by trillions of minute spiritual particles (micro-micro particles). In theology, "spiritual vision" has become an umbrella term that includes all forms of non-ordinary subjective experiences without distinguishing inward apparitions from introvertive spiritual ones or from outward apparitions at a physical site. Such a scenario may be confusing, and it may also undermine the higher-order apparitional experiences of an untainted, non-physical nature.

Both forms of spiritual visionary experience have played a pivotal role in the evolution of cultures. John Perry argues that cultural turmoil galvanizes the psyches of many individuals, leading to spiritual visions, and that sometimes creative cultural novelties arise from this progression [16]. Joseph Campbell has traced the process whereby new visions, often expressed in new myths, have guided human cultural evolution [17]. He has opined that primitive men's fascination with fire, then with the animal world and the world of the planted seed, started with introvertive spiritual experiences and their interpretation. Campbell points out that this progression was followed most recently by our fascination with the planets and the stars.

Emmanuel Swedenborg (1688-1772), St. Teresa of Avila (15151582), and St. Faustina (1905-1938) are a few of the historical figures who have had introvertive spiritual visions as well as inward apparitional experiences. To those who want to develop an extended model of consciousness, the non-ordinary experiences of the sages of the bygone days are precious, and these three spiritual explorers scan the inner spiritual dimensions rather in the way the Hubble Space Telescope scans the infinity of space. Swedenborg was a scientist who spent the initial two-thirds of his life in scientific pursuits and devoted the rest to spiritual quests. He represents a classic example of someone who experienced introvertive and extroversive spiritual visions as well as inner and outer creativity; inner creativity refers to spiritual growth and outer creativity to the 
arts and sciences [18]. The continuum of inner and outer creativity, as demonstrated by Swedenborg, is illustrative of the mediumistic elements in creative works and substantiates the paranormal nature of inspiration.

St. Teresa, a Spanish nun, had several rapturous experiences and developed profound spiritual insights. Her hard-earned spiritual wisdom is remarkably relevant to the modern world. It should be correlated with current scientific knowledge of the aesthetic dimension. Her raptures were like introvertive visionary experiences and akin to inner creativity. She was a genius regarding morality; in her masterwork, Interior Castle, she defines the soul as a "castle made entirely of diamond or of a very clear crystal, in which there are many rooms." Some rooms are above, some below, and some to the sides, and in the center is the main dwelling place where the secret exchanges between God and the soul take place. Teresa wanted to show her students how to pass into this castle-that is, how to pray-so that they might commune more intimately with God. The Polish nun St. Faustina, who was canonized in 2000 by the Polish Pope John Paul II, had outward apparitional experiences with a Roman Catholic cultural construct. Her confused spiritual mentor recorded that he had her examined psychologically to rule out "illusion, hallucination and delusion"; she was certified as healthy.

\section{Apparitions of a higher order}

Apparition ology may be in its early stages of development and the following narrations are an attempt to clarify some of the conceptual confusions however imperfect and uncertain they may turn out to be. There may be two types of apparitional phenomenoninward and outward apparitions. Inward apparitions are equally as important as outward apparitions, but they are psychologically and spiritually more demanding. Six theories of apparition are popular in the parapsychological circle [19], and such multiplicity indicates that there are different forms of visionary experiences without adequate conceptual models. The phantasm genic center theory of apparitions may be useful to explain some inward spiritual apparitions, and clairvoyance theory and telepathy theory may be useful to explain introvertive spiritual visions and not collective visionary experiences. Extrasensory perception-psychokinesis (ESP-PK) theory is useful for explaining outward apparitions at the physical site.

The answer of the spirit control of Daniel Home, the Scottish physical medium of the Victorian period, to the question from one of the sitters of a séance reflects these different theories. The spirit control said: "At times we make passes to augment the field energy (ESP-PK theory) over the individual to cause him see us; sometimes we make the actual resemblance our former clothing appear exactly as we were known to you on earth, sometimes we project an image that you see; sometimes you see us as we are with a cloudlike aura of light around us" [20]. Being highly evolved, the physical manifestations of the Blessed Virgin Mary (BVM) would arguably follow an incomprehensible and "advanced Physics." Out of our helplessness, we need to frame some form of terrestrial standard to develop a conceptual model so that we can bring these celestial visitations into the realm of our scientific imagination.
For parapsychologically uninformed investigators, distinguishing the Medjugorje outward apparitions from inward apparitions may be a challenge, but studying inward apparitions offers some assistance in differentiating between the Medjugorje apparitions and the two forms of spiritual visions. As science is based on empirical observation rather than revelation, our deductions are always subject to modification when new data accrue. The discipline of science does not enable absolute proof about anything. A humanly incomprehensible alternative explanation should be recognized as a possibility even for the most authentic paranormal phenomena, and such a predicament only leads us to a $99.8 \%$ conviction or $0.2 \%$ reservation for even the most convincing paranormal occurrences. Interestingly, this incomprehensibility factor is advantageous for spiritual growth because it calls for the development of a degree of faith. It is the ants in the sugar bottle that stir up the sugar, and in the same way, doubts about faith prompt spiritual searching of faith. Spiritual litmus testing may complement scientific method. The late Professor David Fontana pointed out that the procedure of developing trust and faith is part of spiritual evolution [21].

Scientists are obliged to have some reservations about the unfathomable aspects of mystical occurrences. Theologians have an approximate spiritual model of Marian visions but not an intellectual model, and modern theologians are technically minded. Such a situation is an impediment for theologians to appreciate Marian apparitions. They are the caretakers of Our Lady's earthly appearances. Theologians are expected by the laity to be more infallible than the rest of us, and they are in a vulnerable position when it comes to arriving at a verdict on paranormal and mystical phenomena. Consequently, they tend to postpone their conclusions about subjective experiences. Such a situation is not helpful for the spiritual growth of the larger community, but the messages of the celestial world are urgent; scientists are obliged to offer a helping hand. I have proposed an approximate intellectual model for the study of inward apparitional experiences in this paper, which I trust will not be ignored by the scientific community, who are obsessed with objective and experimental evidence. Spiritual visionary experiences are currently being reported in various parts of the world. Some of the genuine spiritual visionary events happening all over the globe may be considered an extension of what is ongoing at Medjugorje. After all, spiritual dimensions are only a few millimeters away from the terrestrial world, and they are not restricted by space-time sense.

\section{Outward Apparitional Experiences}

Scientists can study only apparitional experiences and the apparition is beyond the parameters of science. True apparitions are outward apparitions at a physical site. Outward visionary experiences are events that appear to the subject to involve the direct perception of spiritual realities - that is, if they are not hallucinations, they must be perceptions of spiritual reality that are somehow factual. During the thirty-eight years of regular apparitional experiences at Medjugorje (Bosnia,1981 to date), natural and self-controlled eye movements and facial emotional expressions and externally controlled voice black-out phenomena (RSPK-like phenomena) are observable and they are outward 
apparitional manifestations. Visionary experiences accompanied by RSPK activities have been designated as true cases of outward apparitional manifestations at the physical site [19]. In cases of outward apparitional experiences of a higher order, the visionaries pay respect to the apparition visibly by kneeling or making some other kind of physical gesture. In the case of inward apparitions, respect is paid psychologically and spiritually. Outward apparitions may occur in a collective way, with more than one percipient; whereas inward apparitions are single at one time, other than in manifestations where there are cross-correspondences to prove the authenticity of the event.

Cognizant of the space-time sense of the terrestrial world and so as not to interfere with the social and daily activities of the percipients and participants, the apparitional figure in outward apparitional manifestations of long duration tends to set a time for their earthly visitations. Such is not the case in inward apparitions as they are very private experiences and outside social norms. At Medjugorje, $6.40 \mathrm{pm}$ is the established apparitional time. In inward apparitional experiences, there is no such set time; they may come as spontaneous appearances. So, also, the figure in inward apparitional experiences seems to oblige the percipients' demands or their own readiness for celestial experiences.

\section{Inward Apparitional Experiences}

Inward visions are experienced through 'inner eyes'; they are not mediated through the physical senses. The visionaries commonly close their eyes to enhance their concentration and attentiveness. One dictionary definition of an apparition is that it is someone you see or think you see who is not there as a physical being. In theory, apparitions may occur at a physical, paraphysical and spiritual level. We need to recognize that, just as there may be outward apparitions, there may be inward apparitions. Inward apparitions are internal subjective visions mediated through interoceptive senses and may be similar to perceptions in the out-of-the body state. These may also take auditory forms. Outward apparitions may be controlling; inward apparitions are less controlling. Inward apparitions may be independent of any extraordinary psychical abilities, but such abilities become activated in long-term visionary events There is no observable verbal communication in inward apparitions; communication takes place through thought transference. Unlike in outward apparitions at physical sites, RSPK activities are not observed in inward apparitions. Such phenomena are not to be expected from the percipients of inward apparitions as they are taking place in a personal subjective space. In that way, inward apparitional experiences have a distant similarity with mental mediumship. It may be true that the term 'mental mediumship' generates impatience among theologians, but inward apparitional experiences do have elements of mediumship of a higher order.

In inward apparitions, the presence of the external agency is perceived in a non-sensual and direct way, whereas the percipient of introvertive visions may not be aware of such a presence Synchronicities, observed in cases of collective outward apparitions, are not detectable in inward apparitions. The external agencies in inward apparitional cases may validate their manifestation through circumstantial evidence, the fulfilment of predictions and powerful messages, and in isolated cases through cross-correspondence. They may also demonstrate their credibility by offering verifiable information that the percipient cannot have gathered through normal channels. There would be an element of inter-subjective agreement to general acceptance of the phenomenon. Such apparitional experiences are person centered and independent of any physical site, whereas outward apparitions at the physical site are both person and place oriented.

Inward apparitional occurrences are more prone to interpretational and communication errors. They are more liable to-and frequently subjected to-psychological editing by the percipients. Much to the disappointment and disturbance of observers and believers, even in well-documented and scientifically validated outward apparitions such as at Garabandal (Spain 196265), such intrusions have been identified. As in outward apparitional experiences, the percipients are chosen, and the experiences end with the withdrawal of the external agency. Inward visions are reported in mediumship. Such visions are occasionally inserted in the outward Marian apparitional occurrences [20,21]. The third secret of Fatima which is weaved of symbols is an example of visions being superimposed on outward apparitions. Nothing can be more frustrating for the percipients of this category of visionary experiences than nobody believes them and try to medicalize their experiences. The phenomenon occurs in the private courtyards of the mind and no objective evidences may be readily available. Because of the paucity of conceptual models, spiritual visions that require stringent discernment are sometimes mislabeled as outward apparitional experiences. Inward apparitional experiences are no less important than outward ones. To study them, it is mandatory to accept that the human mind may be regarded as a means of communication that involves a receiver and a transmitter, both of which are highly sophisticated [14].

The medical and scientific findings at Medjugorje suggest dual modes of perceptions meaning that there is both interior vision and exterior visions in true Marian apparitions at the physical site whereas theological perspective is that there is only interior perception and no sensual perception. Rene Laurentin observed several synchronistic behaviors of the Medjugorje visionaries while they are having the apparitional experiences [22]. The collective percipience and synchronicities observed in Medjugorje apparitional experiences testify their physical objectivity and outward apparitional status (Table 2).

Dr. Georgio Sanguinetti from the Institute of Criminology of the University of Milan noticed another synchronicity, which is "a fleeting bodily tremor" at the end of the Medjugorje apparitional experiences. I have observed the visionaries eighty times at the time of the apparitional experience and the "fleeting bodily tremor" caught my attention. During my several visits to Medjugorje, I also noticed transient facial movements of perplexity at the end of the Medjugorje apparitional experiences. It appeared to me like the perplexed facial movements when the spectacles are suddenly removed from the eyes of a person with poor eyesight by another person without warning. To use a comparison, at the time of the apparitional experience, the Medjugorje visionaries became like 
someone gifted with a pair of spectacles that have special powers enabling him to see things, which are invisible to others. They go through a transient perplexity when these "Super-Spectacles" are taken away. All the above synchronisms prove that the Medjugorje visionaries are responding to an outside reality and not to an internal stimulus. As the visionaries have become used to the apparitional experience and the apparition, the above synchronisms are not as prominent now as they were in the initial stage of this apparitional occurrence. I think this is to be expected as a natural progression of a healthy paranormal cum mystical experience, which adds to the authenticity of the Medjugorje apparitional occurrences. The visionaries remain natural and are not dramatizing the event to please the pilgrims.

Table 2: Synchronisms at medjugorje.

The Visionaries kneel down together. Their reaction time differs. Ivanka is normally the quickest. The kneeling is simultaneous most of the time.

\section{The voices disappear at the same time}

The voices return at the same time to say, "who art in Heaven." When people asked them why they omitted the first two words of Our Father, their reply was "Our Lady says, 'Our Father' and we follow on." Here again, the synchronisms depend on the reaction time of the visionaries, but these often approach simultaneously.

At the end of reciting of Our Father and the Glory Be, the voices disappear again (they do not say Hail Mary because, they are praying with the Virgin Mary).

At the end of the apparition, their eyes are all raised simultaneously. "The Virgin Mary disappears upwards," they explain the eye movements. (When a person looks at a real moving object and an imagined moving object the eye movements are different and the eye movements of the visionaries at the end of the apparition correspond to the former which I have witnessed myself in Medjugorje).

One or several of the visionaries explain more or less simultaneously "Ode" which means she is gone.

According to the electro-oculogram recorded simultaneously for visionary Ivan and Marija, the eyeballs are mobile before the apparition, just as they are in ordinary life. From the onset of the apparitional experience, within one fifth of a second, this movement ceases. At the end of the experience, the eye movements reappear at the same time, again within one fifth of a second.

Parapsychologists can now argue in favor of two forms of apparitional experiences, namely inward apparitions and outward apparitions with physical components whereas theologians are close minded with interior perceptions only. Thus, parapsychological perspective may be described as having both outward and inward apparitional experiences in the classical types of Marian apparitions. The fundamental difference between spiritual visions and true apparitional experiences of inward and outward variety is that the former is self-generated, and the latter is externally generated (Table 3). The theological anthropology and cognitive sciences come close to each other in the Marian apparitional studies.

Table 3: Spiritual visions, Inward and outward apparitional experiences.

\begin{tabular}{|c|c|c|}
\hline Spiritual Visions & Inward Apparitional Experience & Outward Apparitional Experience \\
\hline 1.Selfgenerated & 1.Externally generated & 1. Externally generated \\
\hline 2.Under voluntary control & 2.Not under voluntary control & 2.Not under voluntary control \\
\hline 3.Person cantered & 3. Apparition centred & 3. Apparition centred \\
\hline 4.Not place centred & 4.May or may not be place centered & 4.Manifestation at the physical site. \\
\hline $\begin{array}{l}\text { 5. May be vivid and clear, but lacks the substance of } \\
\text { perception, may mimic perception. }\end{array}$ & $\begin{array}{l}\text { 5.May be vivid and clear, but lacks the sub- } \\
\text { stance of perception, may mimic perception }\end{array}$ & $\begin{array}{l}\text { 5.Vivid and clear and has the substance of } \\
\text { perception. }\end{array}$ \\
\hline \multirow[t]{2}{*}{$\begin{array}{l}\text { 6. No recurrent spontaneous psychokinetic activity } \\
\text { (RSPK) 7. Can be distracted }\end{array}$} & $\begin{array}{l}\text { 6.No recurrent spontaneous psychokinetic } \\
\text { activity (RSPK) }\end{array}$ & $\begin{array}{l}\text { 6.Recurrent spontaneous psychokinetic activi- } \\
\text { ty (RSPK) may be present. }\end{array}$ \\
\hline & 7.Cannot be distracted & 7.Cannot be distracted \\
\hline $\begin{array}{l}\text { 8.Elements of extra-sensory perception (ESP) may be } \\
\text { present. }\end{array}$ & 8.ESP is activated by external argent. & 8.ESP is activated by external argent \\
\hline 9.Inner vision & 9.Subjective cum objective perception & $\begin{array}{l}\text { 9.Subjective cum objective and objective } \\
\text { perception }\end{array}$ \\
\hline $\begin{array}{l}\text { 10.Dreamlike, not emanating its own light, not lumi- } \\
\text { nous, not solid }\end{array}$ & $\begin{array}{l}\text { 10. Ethereal or astral origin, luminous and } \\
\text { self-emanating light observed, unambiguous } \\
\text { and solid }\end{array}$ & $\begin{array}{l}\text { 10. Ethereal or astral origin, luminous and } \\
\text { self-emanating light observed, unambiguous } \\
\text { and solid }\end{array}$ \\
\hline 11.Not interactive & 11.Intearactive & 11.Interactive \\
\hline $\begin{array}{l}\text { 12. Cannot be photographed, will not reflect on the } \\
\text { mirror }\end{array}$ & $\begin{array}{l}\text { 12. Cannot be photographed, will not reflect } \\
\text { on the mirror }\end{array}$ & $\begin{array}{l}\text { 12. Rarely photographed, and reflect on the } \\
\text { mirror }\end{array}$ \\
\hline 13. Movement of the figure restricted & 13.Movement of the figure restricted & 13.Movement of the figure not restricted \\
\hline 14.Personal intent may be present & 14.Special intent present & 14. Special intent present \\
\hline
\end{tabular}




\begin{tabular}{|c|c|c|}
\hline $\begin{array}{l}\text { 15.No independent intelligence and consciousness } \\
\text { involved }\end{array}$ & $\begin{array}{l}\text { 15.Independent intelligence and conscious- } \\
\text { ness involved }\end{array}$ & $\begin{array}{l}\text { 15.Independent intelligence and conscious- } \\
\text { ness involved }\end{array}$ \\
\hline 16.Movement of the figure restricted & 16.Movement of the figure restricted & 16.Movement of the figure is not restricted. \\
\hline $\begin{array}{l}\text { 17.Brain chemistry or psycho-spiritual factors respon- } \\
\text { sible. May be atmospheric apparitional experience, } \\
\text { telepathic hallucination or out-of-body figure }\end{array}$ & $\begin{array}{l}\text { 17. Independent of the brain and discarnate } \\
\text { agent may be responsible }\end{array}$ & $\begin{array}{l}\text { 17. Independent of the brain and discarnate } \\
\text { agent may be responsible }\end{array}$ \\
\hline 18.Sensory disconnection & 18.Partial sensory disconnection & 18.Partial sensory disconnection \\
\hline $\begin{array}{l}\text { 19.May be coloured by complex scenes of the past or } \\
\text { fragments of action relevant to the emotional past of } \\
\text { the individual, within the limits of imagination }\end{array}$ & 19.Cultural construct is nominal & 19.Cultural construct is nominal \\
\hline 20.Identity may be unclear. & 20.Identity may be revealed & 20.Identity may be revealed \\
\hline 21.Consciousness may be impaired & 21.Full consciousness & 21.Full consciousness. \\
\hline 22.Repetitive and stereotyped & 22. Not repetitive or stereotyped & 22. Not repetitive or stereotyped \\
\hline 23. Not confined to a single sensory modality & $\begin{array}{l}\text { 23. Visual and auditory modalities are most } \\
\text { common. }\end{array}$ & 23. Visual modality is most common. \\
\hline 24. Partial insight & 24. Insightful & 24.Insightful \\
\hline 25. My not have any new information & 25.New information received & 25.New information received \\
\hline 26. Occurs at a reading distance & 26. Distance is not relevant & 26. Distance is variable \\
\hline 27.Continuum between creativity and spiritual visions & $\begin{array}{l}\text { 27. Continuum between inward and outward } \\
\text { apparitions }\end{array}$ & $\begin{array}{l}\text { 27. Continuum between inward and outward } \\
\text { apparitions. }\end{array}$ \\
\hline 28. Closely linked with quantum consciousness & 28.Linked with higher consciousness & 28.Linked with higher consciousness \\
\hline
\end{tabular}

\section{Not Hallucinatory Experiences}

Scientists who dismiss spiritual visions as hallucinations forget that visual hallucinations are commonly indicative of neurological conditions and rarely of psychopathology. Visual and auditory hallucinations are visual and acoustic holograms of parallel/ quantum thinking and not emanating from the spiritual body [23]. Stimulant drugs that may bring about isolated spiritual visions are sometimes used for psychotherapeutic purposes in experimental situations. Recent interest in the neurological substratum of religious experiences is a development that does not come close to explaining the variety of spiritual experience. Long-term spiritual visionary experiences are likely to leave a trail in the physiology of the brain, but that does not mean that those biological alterations generated them-footprints and shadows are created; they do not create the person who generated them. The holy war between upward causation and downward causation still goes on among the cognitive scientists.

Theologians have a 'top-down' approach to spiritual phenomena, tending to rule out abnormal spiritual experiences rather than considering that an incidence may be an authentic transcendental event. Often, they are concerned about diabolical intervention and examine the possibility that 'astral actors' are involved in externally generated spiritual visions. Perceptual spiritual experiences - that is, visions - are not necessarily pathological. Most often, they are introvertive spiritual experiences of a personal nature.

\section{Marian apparitions}

A Marian apparition is a supernatural appearance of the Blessed Virgin Mary, the mother of Christ, to a person or group of people on Earth. Several hundred apparitions have been recorded as occurring in modern times, with Our Lady claimed to have appeared on nearly all continents in the latter half of the twentieth century. My view is that, although many of those events were intense human spiritual experiences in the form of spiritual visions, a few of them may be designated as inward apparitional experiences but not necessarily outward apparitional occurrences, such as the archetypical events at Lourdes and Fatima.

Parapsychology has recently opened its frontiers to encompass the spiritual or the mystical, but the transcendental aspects of Marian apparitional phenomena are beyond the parameters of scientific research. Unlike a hallucinatory figure, the Marian percipients see a talking apparition in an objective space with a purpose, and those apparitions are three-dimensional and active. The apparition takes up the percipients, and the meeting between those involved is not mechanical. The quantitative scientific tests conducted by the French and Italian medical teams at Medjugorje prove that the visionaries are responding to an outside agency [24]. The voice extinction and sensory disconnection of the percipients demonstrated at Fatima and Medjugorje and at other Marian apparitional sites could be explained as psychokinetic-like activity on the part of the apparition, and visionary experiences involving RSPK or RSPK-like activity may be instances of true apparitions at the physical site. Marian apparitional experiences may constitute evidence for the existence of psi-like phenomena and discarnate survival.

Neuroscientists who are confused about neurological theories of mysticism would benefit by studying Marian apparitions in order to understand that, in addition to sensory consciousness, we may have a "spiritual or higher consciousness." The finding that an apparition has survived for two millennia and has allegedly appeared and communicated with people at different sites may also support the thinking that our consciousness may survive physical extinction. Apparitions of Mary are as valuable for the scientific community as they are for the theologian. Marian apparitional experiences can be 
subjected to scientific analysis, but Marian apparitions are beyond scientific parameters. Marian apparitional events inform research into post-mortem existence and offer a complementary insight into our current knowledge of the discarnate realm. Science does not prove Marian apparitions, but it offers a pointer toward proof of them. Like the visions at Lourdes and Guadalupe, the Medjugorje visions are self-validating apparitional occurrences that involve the fulfilment of a promised visible sign. Here, I am only discussing Marian apparitions relevant to survival research.

\section{Medjugorje, discarnate existence}

An important series of apparitional occurrences has been continuing at Medjugorje in Bosnia since 1981.To begin with, these apparitions occurred to a group of six visionaries and continue today. A French and an Italian medical team examined them separately and established simply that the visionaries are responding to some external stimuli. The present author has made observational studies of these apparitional events since 1985. If parapsychological and theological observations are added to the medical findings, these visionary experiences could be considered authentic Marian apparitional experiences. More than 40 million people have visited this place in the last 38 years. Parapsychologists who are not interested in these phenomena may be like astrophysicists who are not interested in the rare appearance of Halley's Comet. Medjugorje has been amply written about.

The Medjugorje visionary experiences have been amply documented from 1981 to the present day [25,26]. Craig Lundahl has made a daring correlation between the phenomena at Medjugorje and the views of those who describe post-mortem existence as consisting of two major divisions, with the possibility of a third [4]. Mother Mary has offered information about different forms of discarnate survival through the percipients of Medjugorje and has given them glimpses of post-mortem conditions-heaven, purgatory, and hell [26]. Heaven is a richer reality of time, a state of fullness in which past, present, and future are blended harmoniously. Unlike physical personalities who live in the space-time dimension, discarnate personalities trapped in the timeless dimension (purgatory) cannot bring about change in their personalities swiftly and could be trapped in that stage for centuries. There are different levels within this dimension, and they tally with Robert Monroe's description of the four locales found in his extra-somatic voyages $[27,28]$. They also match the Austrian clairvoyant visionary Maria Simma's suggestion of three planes in purgatory [29]. Simma, whom I visited at her mountain house in Sonntag, claimed to have had visitations by the "poor souls" from purgatory for several decades [29]. She used to have the apparitional experiences probably at a quantum level and not necessarily at the physical site. Purgatory is re-educating oneself with the old syllabus, but according to Simma, the souls in the lowest plane are highly vulnerable to tortures from negative entities.

Marian apparitions have also reaffirmed the existence of negative and positive entities. All the Medjugorje visionaries were shown heaven, purgatory, and hell in visions, except Mirjana Drgicevic and Ivanka Ivankovic, who did not want to see hell. Two of the seers, Vicka and Jackov, claimed that they were teleported to other realms by the apparition. Young Jackov said he initially resisted having to leave his mother alone [25]. H.M. Brown recounted that Vicka and Jackov were bodily transported to these realms, during which they reportedly disappeared for 20 minutes [30]. When I interviewed the visionary Ivan Dragicevic, he insisted that he had not undergone an OBE but a full bodily transportation, in which travelling brought him to scenes of paradise. He questioned whether such things as OBEs really exist as he had never heard about NDEs. According to Vicka and Jackov, they had experienced a true transportation. None of them claimed to have encountered the light being or any historical biblical figure. Neither the third division nor the features of hell-a realm described by some Marian visionaries-has been established or delineated in NDE studies. The visionaries asserted that this realm has a particular environment that is occupied by strange people.

Ivanka Ivankovic, another Medjugorje visionary, claimed to have had the privilege of seeing her deceased mother Jagoda with the assistance of the apparition. She reported that this was like a vision superimposed on another vision. She declared that she has not a grain of skepticism about the continuity of life after death. Her mother died unexpectedly and alone in May 1981 at the age of 39, before the commencement of the apparitional occurrences, owing to an attack of bronchial asthma. Ivanna's last daily apparition was on May 7, 1985. She said that on that occasion, she saw her deceased mother for the third time. She claimed that she saw her dead mother for the first time in June 1981 during her usual apparitional experience. The confident words of Ivanka from an interview I conducted with her are quoted as follows: "All of us ask ourselves, is there life after life? I am standing here before all of you as a living witness, and I can tell you there is life after life because on that day in May I was able to see my late mother. I was able to hug her, and my mother told me, 'My daughter, I am proud of you.'” Amateur critics of Medjugorje cited Ivanka's bereavement as the triggering factor for her visions there. Pseudo-hallucinations relating to bereavement take place in surroundings that are familiar to both the individual subject and the deceased. Moreover, instances of so-called collective pseudo-hallucinatory experiences are not collectively perceived, but one person experiences them and others merely share the idea without experiencing the hallucination.

Teleportation involves destroying an object and recreating itdematerialization and materialization. So, the term "teleportation" may not be appropriate in this context, but we have no substitute for it. According to Vicka, she walked only a few meters with the apparition to enter into the new dimension. Therefore, it was not a distant travel ("tele" means distant). The visionaries were physically transferred to another dimension, an inter-dimensional transportation. I cannot anticipate any physicist explaining the mechanism of this inter-dimensional transfer at the moment, and I cannot disbelieve the visionaries, whom I have known for a long period. I simply conjecture that it could have also involved some form of gravitational anomaly as gravitation and electromagnetism are two forces that could influence macro objects. 
It may be hypothesized that the "mystical transportation" reported by the Medjugorje visionaries may have also encompassed a gravitational anomaly, in the sense that the visionaries were conveyed out of the physical dimension and had "physical experiences" in another dimension, breaking the normal laws of gravitation. Such a phenomenon indicates that the apparition is capable of causing powerful effects on the gravitation (gyrokinesis) and, hypothetically, is proficient enough to generate "an as yet unknown passage," like a miniature black hole or wormhole for the claimed inter-dimensional transfer. Historically, gravitational anomalies have been reported at other Marian apparitional sites. In the alleged Garabandal Marian apparitions (Spain, 1962-1965), gravitational anomalies occurred in the form of unexplainable weight gain and weight loss of the visionaries during their apparitional experiences [31,32]. The mechanism involved in an increase of weight is the reverse of levitation; both are gravitational anomalies.

\section{Lessons from visions of Medjugorje}

I have expressed my support of the authenticity of outward apparitions at the physical site in Medjugorje in all my papers on the subject [33,34]. The study of the outward Medjugorje apparitional experiences has given me the impetus to examine other forms of visionary experience. Quantitative assessments carried out by the medical team engaged with the Medjugorje seers have established that dual modes of perception by the apparitional figure occur during the apparitional experiences [22]. Theoretically, visionary experiences may occur as ordinary sight visions, non-physical objective visions, and subjective visions. Non-physical objective visions and subjective visions that have been proved scientifically at Medjugorje point toward the probable occurrence and authenticity of inward apparitions as well as introvertive spiritual visions in other scenarios.

Ordinary sight visions involve ocular stimuli and physical illumination; objects and physical lights are perceived as though the appearances are part of the earthly realm (physically objective). However, perceptions of apparitional figures most often occur without physical illumination-even in darkness-that is, objectively and externally (non-physically objective). Within this scenario, the apparitional figure would be visible to those who are specifically permitted to see it. Subjective visions are centrally stimulated perceptions without ocular stimuli in the absence of physical illumination and may contain paranormal components as in true introvertive spiritual visions. Subjective pseudo-visions occur in altered states of consciousness, owing to internal stimuli of the person, such as in purely subjective dreams, hallucinations, and so on. In other words, there may be true introvertive spiritual visions and false ones as well.

In the occurrence of an objective non-physical sighting of an apparitional figure, the psychokinetic-type powers of the apparition effectively illuminate the ocular apparatus of the percipient. What happens is analogous to illuminating someone in darkness by directing a powerful beam toward them from a torch. Furthermore, apparitions have a tendency to discriminate; they may direct their psychokinetic powers to selected persons, excluding those who stand alongside them. The apparition is capable of illumination and of selectivity. When the apparition is the physical manifestation of the BVM, more features that we may term "black-out phenomena" are identifiable during the paranormal event. The distinctly observable voice black-out of the percipients is described above. As the voice of the apparition is not heard by the witnesses to the events but is heard by the visionaries, it is accurate to say that the BVM performs a selective acoustic black-out of herself during her manifestations. It is of note that there is a partial sensory blackout of the external physical world on the part of the percipients. When there is an apparition that we consider authentic, there is also an apparent visual black-out of the heavenly personage to the witnesses around the percipients. In my view, all forms of blackout-that is, acoustic, sensory, and visual-may be outcomes of the psychokinetic-like powers of the apparition. The acoustic and sensory black-outs of the percipients have been medically tested while the other two forms of black-out are not testable but only assumptions. Both exteroceptive and interoceptive senses are involved in Marian apparitional experiences, and they result in objective and subjective visions. In the Marian visions at Medjugorje, there are paranormal objective-external and subjective-internal perceptions of the apparitional figure. The medical findings conducted support the dual modes of perception [22]. The findings of subjective-internal and paranormal perception open up the possibility of inward apparitional experiences occurring in other situations.

\section{Fatima (Portugal)}

The Fatima visionaries in Portugal in 1917 were also shown a vision of hell, and the Marian apparition at Fatima made mention of the realms of bewildered spirits and heaven. An apparition may provide evidence of the authenticity of its manifestation at a physical site by offering predictions that are to be fulfilled at a later date. One of the distinctive features of the events at Fatima is the fulfilment in our own time of the predictions made. Lucia Santos was the principal percipient of the Fatima apparitional occurrences. The others were her cousins Francisco and Jacinta Marot. All three were from poor but respectable families. On May 13,1917 , these children were caring for the sheep that belonged to their families in their village near Fatima when they saw "a Lady, all of Light" above a small oak tree. At that time, they were grazing the sheep on a piece of land owned by Lucia's parents at Cova da Irian, a natural amphitheater about 500 meters wide. The apparition asked them to return to that place on the thirteenth day of each month for the next five months. She promised the children that a great miracle would be performed in October, so that everyone would believe in her appearances and in the messages she gave. The lady also confided to them special messages that were to be revealed later. Each apparition lasted about 10 minutes. From the second one onwards, they were witnessed by an ever-increasing number of onlookers. Some 70,000 people saw the promised miracle that immediately followed the sixth and final appearance. In the Fatima visions, light as God is mentioned. Sister Lucy wrote: "When pronouncing these words, 'God's grace, etc.,' she opened her 
hands for the first time, shedding onto us a very intense light, like a reflection coming from them, penetrating our hearts and the depths of our souls, showing us ourselves in God. He was that light, and we saw much more clearly than in the finest mirrors" [35].

It was on July 13, 1917 that the apparition confided the three special messages-or the secrets, as they are popularly known-with the instruction that the children were not to talk about them to anyone at that time. The first secret is a vision of a negative realm and is presented in a symbolic way. It was as if a vision were inserted into a vision. Sister Lucia described it as follows [35].

She opened once again her hands, as in the previous two months. It seemed that the reflection penetrated the earth and we saw what seemed an ocean of fire; plunging in this fire were demons and souls like transparent burning coals, black or bronze, with human form, floating in the fire, driven by flames coming out of themselves, together with clouds of smoke falling on all sides, like the sparks falling in great fires, with no weight and no equilibrium, amidst screams and groans of pain and despair that horrified us and made us tremble with fear. Probably it was when I beheld this sight that I uttered that 'Woe' people say they heard. The demons were of varied forms, horrible, disgusting and unknown animals, but transparent like black incandescent coals.

In an interview with a high-ranking member of the church hierarchy, Sister Lucy reaffirmed her vision of hell, but interpreted hell fire as a supernatural fire, not a physical fire, and one that cannot be compared to any fire that burns from wood or coal [36]. Obviously, a symbolic presentation is hard to interpret in terms that others will find easy to comprehend. Francisco, one of the Fatima percipients, could not initially see the apparition. He was instructed by the figure to pray more. He did that, and subsequently, he was able to share the apparitional experience. Such a scenario is analogous to the visionaries who claim that the level of the dimension they travel is dependent upon the energy levels and the frequencies of light in the spiritual body of the individual. The apparition said to the Medjugorje visionaries that the laws of nature could be suspended through prayer augmented by fasting [25]. Hypoglycemia induced by fasting may help the brain to become underactive in order to facilitate better spiritual tuning.

Alfred et al. [37] attempted to shed light on certain features of Fatima apparitional occurrences in terms of dark plasma theories, thereby bringing Marian apparitions into the realm of the physicist's imagination [37]. It has been recorded that during the preparatory phase of Fatima apparitional occurrences, the percipients saw across the valley a dazzling globe of light like a miniature sun, gliding slowly toward them. As it approached, the ball of light gradually resolved itself into a brilliantly shining transparent young man, "who was more brilliant than a crystal struck by the rays of the Sun." He disappeared by fading away. Alfred et al. [37] noticed that magma bodies can change their degree of opacity, and it is a wellknown fact in metaphysical literature that super magma bodies can change their appearances at will. These changes may occur on the surface of magma bodies and may be very superficial. Alfred et al. [37] argued that the super magma body may be using a technology that is similar to plasma-vision and LCD technology combined.
It has been documented that on September 13, 1917, an assembled crowd saw a bright ball in the sky coming from the east, which glided majestically into view for a few seconds but then vanished, as far as the crowd was concerned. The visionaries, however, saw a luminous globe perched on a little oak tree. The Virgin spoke to the visionaries and then returned the way she had come-in the shape of an easily visible luminous ovoid moving away in the direction of the Sun, calmly but with a certain speed, before fading. Lucia, the eldest among the seers of the Fatima apparitions of Our Lady, stated that during one of the apparitions, Our Lady opened her hands and rays of light emanated from them. Alfred et al. [37] argued that this may have been done simply by increasing the rotational speed of the "chakra" in the palm by an act of will, causing charged super particles to rapidly swirl around an intense magnetic field, radiating energy, which was directed by the magnetic field aligned with the jet. The above conjectures are purely hypothetical and a physicist's attempt to comprehend the incomprehensible, but useful to bring Marian apparitional experiences to the attention and appreciation of the technically minded.

\section{Kibeho apparitions (Rwanda)}

The Kibeho apparitions of Rwanda (November 28, 1981-November 28, 1989) have a typical African cultural flavor. On November 28, 1981, Alphonsine Mumureke, a pious 16-yearold student, was suddenly called by a voice saying, "My child!" From then, Our Lady began appearing to her and called herself "the Mother of the Word" [38]. There was considerable criticism at the beginning, and Alphonsine was put into a sort of quarantine. Marie-Claire Mukangango, one of the skeptics, was also called by Our Lady. Events gathered momentum and crowds gathered. They had to put up a kind of raised platform so that the apparitional experience could take place in full view of thousands of pilgrims and those who had come out of curiosity. National TV lent them a loudspeaker system to allow the enormous crowds to hear the visionaries' answers.

When Our Lady appeared, she wore a long white dress and sometimes a blue veil. She was neither white nor black, but some indescribable color, and she was very radiant. She sometimes wept and was sometimes happy. The visions are authentically African. The visionaries sometimes danced, sang, or composed prayers, and the crowd often joined the great waves of powerful prayer. The visionaries looked at one particular point in front of them unwaveringly. They were insensitive to pins being driven into them as far as the bone, and to burns and thumps. They were in another world. When the apparitions finished, the visionaries sometimes had ecstatic falls, which looked frighteningly painful but left no visible marks on them. During the apparitions, they sometimes cried, knelt, stood up, or lied down. They sometimes had animated conversations with their heavenly visitor, or there were long periods of silence.

The attitude of the local bishop was very open; he set up a medical and theological commission, and he also gave permission for a book to be written on the subject. The findings of the medical commission thus far are that the teenagers were perfectly normal and the long fasts inexplicable. Dr. Muremyangango Bonaventure, 
the Rwandan psychiatrist, certified that the visions were not due to any mental aberrations and even promoted the Kibeho apparitions in the later years of his life [39]. To add to the authenticity of the Kibeho apparitions, one of the predictions of the apparition literally came true. The Rwanda genocide (1994) that claimed 800,000 victims, as predicted in the Kibeho apparitions, is another example of a fulfilled Marian prediction [40]. During one of the apparitional experiences on August 19, 1982, Alphonsine Mumureke was shown a vision of a river of blood, indicating a future catastrophic event awaiting their country. Ilibagiza (2008) wrote [38]: "Suddenly Alphonsine let out a gut-wrenching scream that cut through the startled crowd (nearly 20,000 people) like a razor- 'I see a river of blood! Why did you show me so much blood?' the seer cried out, as Holy Mother revealed one horrifying vision after another." The young visionary was subjected to so many images of destruction, torture, and savage human carnage that she pleaded to stop the visions. Even though predictions in the form of symbolic visions are conditional, most sadly, the Kibeho predictions came true, and the local bishop gave official recognition to the Kibeho apparitions in May 2001. Two of the Kibeho visionaries were also privileged to have otherworldly visions. Ilibagiza Immaculée, who was one of the observers at Kibeho from the very beginning, gave a detailed account (2008) of their otherworldly guided expeditions [38]. The seers' direct personal awareness and contact with celestial dimensions have similarities to and differences from both other reported NDEs and astral travelling. Alphonsine Mumureke, who was a student at Kibeho College in Rwanda during the apparitions and the first visionary to see the Virgin, was told in advance that Our Lady would take her to travel with her. On March 20, 1982, Alphonsine announced to one of the sisters, the director of the college, and one of her classmates that she would appear to be dead, but that they were not to bury her as she had been promised by an apparition that she was to be taken on a mystical voyage. As preannounced, Alphonsine was found lying in her bed the following day. The subsequent commission of enquiry, which included medical experts, was told that all possible tests had been done to ascertain whether she was dead or in a deep sleep. Four men tried rolling her on to her side, but they couldn't move her. Then, six men together tried to lift the slim teenager but in vain (she weighed approximately $200 \mathrm{lb} / 90 \mathrm{~kg}$ ).

As indicated in the preceding paragraph, gravitational anomalies add to the authenticity of the apparitional experiences. The occurrence of externally induced gravitational anomalies implies that the apparition is capable of exerting a powerful influence on the force of gravity and suggests that the events may involve a psychokinetic type of phenomenon [40]. Alphonsin woke up after 18 hours of the externally induced death-like sleep and described her experiences over that passage of time. She recounted that she was initially transported to a very dark zone filled with shadows and groans of sadness and pain. She was taken to many other planes across the stars until arriving in a place of golden light filled with happiness and laughter, in which she could hear songs sung by many joyous voices; however, she could not see anyone singing. When she asked Mary why she could not see the happy souls, Our Lady replied that she could not glimpse them because of her terrestrial status.
Anathalie Mukamazimpaka, another Kibeho visionary, was also privileged to have mystical voyages to other dimensions. At the end of a five-hour experience, she collapsed to the ground, her limbs having become frozen with the same rigidity that Alphonsine had experienced. That marked the beginning of a seven-hour expedition to different dimensions, accompanied by Mary. In the first world, they visited landscapes of varying shades of vivid colour and light, in which spirits travelled from place to place by sliding through the light. The description is reminiscent of the upper astral dimension or Summerland mentioned in survival research literature [41]. Another unusual land visited by Anathalie was illuminated only by white light. Here, she saw seven handsome men wearing white cloaks, who were creating the most melodious music without any instruments. Our Lady described it to her as the place of communion and told her that the men were angels watching over Earth and ministering to humanity.

Anathalie recollected that she floated to another three different worlds with Mary-who identified herself as the Mother of the Wordeach of which had its own characteristic color and light. The plane next to the dimension of angels was also a blissful place; there, she saw millions of people dressed in white. It was described as the place of the cherished of God. From there, they moved to a world in which the light was as dim as dusk. Although the people who inhabited this dimension were apparently content, they also appeared to be sad and suffering-this was the place of purification. The last place they visited was a land of twilight where the only illumination was an unpleasant shade of red. It reminded Anathalie of congealed blood and there the inhabitants were thoroughly unhappy. Their anguish pained her intensely and Anathalie recognized it as hell. The extra-somatic voyages of the Kibeho visionaries would make sense to those who are familiar with Robert Monroe's trilogy and his para-physical and transcendent extra-somatic experiences, which have inspired particle physicists. Maria Simma also had encounters with poor souls from purgatory, and they described their situation as having three planes [29]. The pre-heaven stages revealed by Marian visionaries and by Maria Simma encapsulate a parallel with the "three rings" of Monroe. The Kibeho apparitions were very much adapted to the prevailing local culture.

In the La Salette apparitions that took place in France in 1846-as well as at Fatima and Medjugorje-there is an indication of a new era in human history, marked by human brotherhood, universal love, and peace [42]. A small number of people who have had deep NDEs have reported consistently prophetic visions revealing the future of the planet. These encompass geophysical changes, meteorological changes, economic collapse, and a new era of world peace $[43,44]$. This kind of prophetic vision of a period of peace may tally with Marian apparitional predictions. No one can deny the fact that these predicted events are occurring and that others may follow, even though the majority of the world is not cognizant of them.

\section{Beyond Quantum Consciousness}

Assessing celestial events using terrestrial methods is often challenging. Such undertakings were originally within the compass of theologians and philosophers. While cognitive scientists tend to dismiss all forms of experience that are beyond the everyday 
by classifying them as hallucinations, theologians adopt the more nebulous term "spiritual vision" to account for complex and perplexing higher-order apparitional occurrences. Research into spiritual visionary experiences is significant in consciousness studies because of its potential to offer evidence of the co-existence of extended consciousness or spiritual consciousness along with consensual consciousness.

Mental health professionals are highly vulnerable to medical reductionism as they regularly encounter the powerful effects of psychotropics on the brain and the associated mental alterations; they tend to conclude that there is nothing beyond the brain. Deathrelated visions and Marian apparitions prove to us that it is time to change directions in science, and they are phenomena occurring beyond the quantum consciousness, exploding the reductionist and ultra-reductionist views. Science is open ended and there is always a possibility of modifying, falsifying, and confirming scientific ideas with new data. Sigmund Freud was one of the prominent explorers of the mind. However, along with other scientists, he contributed badly to the pessimism and despair of the modern world. Medjugorje studies prove that science and spirituality can work together to find the truth, and a reconciliation between science and religion that have presented divergent and contradictory world views could be achieved [45].

We need to unpack the brain-mind-consciousness complex to understand and appreciate mystical experiences. The concept of quantum consciousness alone is inadequate to comprehend the spiritual and spiritistic aspects of human experiences. We may also have to postulate that a higher, quantum-like consciousness is downloaded (incarnated) into the quantum consciousness. Such a supra-consciousness micro-particle (spiritual consciousness) may be capable of receiving and sending messages to the living and discarnate consciousness and possibly interacting with it when the brain is underactive. The physical body may be the outer layer of a ring of energy bodies bonded through gravitational force; in death, the gravitational bond breaks and the outer layers are discarded.

Reductionism is the assumption that nothing can be greater than the sum of its parts-the whole is the same as the sum of the parts. An intellectual battle has always been pitched between the adherents of reductionist and non-reductionist ideologiesthe whole is greater than the sum of its parts. Subjective human attributes such as ethics, morality, feelings of respect for others, feelings of self-dignity, ability to trust each other, poetic sense, creativity, and goal-oriented behavior are attributes of a spiritual body in isolation. Unconditional love, empathy, and compassion are part of the spiritual dimension. In the reductionist view, the mind is an epiphenomenon-caused by physical phenomena and incapable of causing anything.

A rainbow shimmering above a waterfall is thought to be an analogy. Other popular analogies of the reductionist view of the mind are comparing it to the froth of a beer or the steam coming out of a locomotive engine-epiphenomenalism. A non-reductionist could argue that such a view is like believing that an Olympic pool created the swimming events held there. In the twentieth century, the brain was accorded more significance than the mind; to reductionists, consciousness is nothing more than a causally ineffectual by-product of the grinding of our neural machinery, of which nobody is in charge. Neuroscientists have been criticized for diminishing the mind to a scientific nullity, making consciousness a subjective illusion.

In the mid-twentieth century, computationalism became a prominent corollary to cognitive psychology. The non-reductionist view is that with the recent growth of meta-analysis, all the basic phenomena of experimental parapsychology, extrasensory perception, psychokinesis, and so on have been justified by statistical analysis; they challenge a materialistic model of the mind. There is evidence from survival research to support their case. For reductionist views to be successfully challenged, it has to be established that minds can exist independent of the brain. One way of proving that humans have a non-physical part in association with the brain that can also exist independent of the brain is proving post-mortem existence. According to survival researchers, there is now as much evidence to justify belief in life after death as there is for the historical existence of dinosaurs. If we add the scientifically examined Marian apparitions of the twentieth century to this corpus of evidence, we then have compelling evidence to believe in the reality of discarnate existence.

The reductionists have to accept the limit of their approach to phenomena like NDEs, collective apparitional experiences, deathbed visions, supernormal states, certain kinds of mediumship, children remembering previous lives, electronic communications, etc. [46-49]. There is mounting evidence to support the claims of enhanced cognitive faculties in NDEs when the brain is truly underactive. Whether memories can outlive physical extinction is a matter of scientific significance. At Medjugorje, the visionaries claimed that the apparition revealed to them her terrestrial memories. There is a tendency among neuroscientists to write off all religious experiences as brain artefact. Such theories have also reduced spirituality to moral and ethical codes of conduct while dismissing the experiential reports of mystics throughout the ages of transcendental realities. Non-reductionists accuse neuroscientists of cannibalizing mysticism. Kelly et al. [50] argued that computational theories cannot explain the introverted mystical experiences of a pure undifferentiated consciousness.

Scientists with Newtonian world views tend to discount the invisible. The view held by classical physicists that two objects cannot occupy the same space at the same time has also been a scientific block to the belief in the existence of a higher dimension associated with the brain. This view, however, is now being challenged by post-Einsteinium physicists [51,52]. Robert D. Klauber [51] asserted that neutrino physics makes the invisible more tangible and brings the non-physical dimensions to the realm of scientific imagination. The misapprehension held by many scientists and non-scientists alike is that the laws of physics are a vestige of pre-quantum mechanical scientific thinking and in no way represent a constraint imposed on reality by the postclassical physics of our modern age. He argued that subtle realms may be made of "neutrino-like particle families" and may co-exist with our physical world without our being aware of them. Similarly, our 
spiritual bodies may be made of invisible neutrino-like micro-micro particles, and there may be other invisible entities formed of such particles. Thus, we may have an ultra-consciousness.

The mind and the brain may be coexisting in the same way that both water and a sponge can exist in the same place at the same time. The minds in the mental space may have the power to interact with other minds, including disembodied ones. Physics promulgates the view that nothing can end abruptly, so physical realms have to continue as paraphysical dimensions and then as a dimension which should have physics that can permit everything to end therespiritual realms; everything should follow the rules of physics. Human beings exist in physical space and in a personal mental space [53]. Human beings may contain a non-atomic energy system incorporated within an atomic energy system. Consciousness may be better explained by a multiple energy system model bonded by nano-level gravitational forces. There is consciousness upon consciousness.

Christ's words "Love your neighbour like yourself" can be better understood if we accept that the spiritual bodies of all humans are like sparks from the Divine Fire or Divine spark-like and there is some form of unity and similarity between all humans- a universal spiritual brotherhood, but Christ is a direct Flame from the Divine Flame. Metaphors reveal only partial truth. 'Aham Brahmāsmi' meaning the God within is a powerful Vedic concept and may be modified as 'Aham Brahmāsmi-like' because in Christian philosophy, human spiritual body is created in the likeness of the Supreme Brahma and carries an image or impression of the Divinity- the factory mark. Recognising 'Aham Brahmāsmi-like' is the ultimate of self-realization and understanding Christ was a direct Flame from the Divine Flame is the beginning of God realization.

\section{Assisted suicide}

The recent scientific evidence suggesting that human beings may survive physical extinction have never been in the equation of the medical debate on assisted dying, even though it is one of its most significant philosophical aspects [54]. This emerging scientific view, coupled with the wisdom of the faith traditions, challenges the rationality of supporting assisted dying that ignores the sanctity of terrestrial existence. Just as Newtonian and Darwinian world views emanating in previous centuries influenced cultural beliefs and attitudes, neuroscience has contributed to the spiritual shallowness of the twentieth and twenty-first centuries. The existential despair of the second half of the twentieth century has been particularly instrumental in promulgating a voluntary death imperative. The moral and ethical dilemmas associated with assisted suicide are interwoven with spiritual concepts because human beings are spiritual personalities and survive after physical extinction. It is the sanctity of life and its sufferings that make assisted dying immoral and unethical. While wrapped in the physical planet by space and time, we are in an advantageous position for inducing personality changes swiftly, whereas in the timeless state of discarnate existence, changes are sluggish and personality development is much slower [54]. Pre-death visions and shared-death visions indicate that deceased relatives and other expert spiritual agencies come to assist the transition of the dying persons [1,9]. People who take their own life may not get such benevolent spiritual assistance; the timing of death is a decision of the spiritual realm and not of the living. The right to die would soon deteriorate as duty to die to prepare room for fittest ones. Suffering is not alleviated by eliminating the patient. Medical professionals who are non-religious and espouse a strict biological model of the mind tend to care less about prolonging life [55]. The majority of British medical practitioners are against assisted suicide [56].

\section{Concluding Remarks}

Subjective experiences like NDEs may elude scientific explanation. Mystical experiences are internal to the experience itself and are self-validating. Those who have had an NDE claim they "know" that there is life after death and do not just "believe" in discarnate survival. NDEs have become an umbrella term for all the unusual experiences associated with death. This includes NDElike experiences and true NDEs of various intensities. In general, NDEs cannot be considered after-death experiences (ADEs) [57], but NDEs of extreme duration or depth may contain a few unarguable elements of ADEs. Even veridical OBEs do not indicate ADEs; they may simply demonstrate that consciousness may exist independently of the brain. NDEs may be indicative of an effectual transitional stage with a debriefing at the end of biological life events that may be succeeded by repair, rehabilitation, and a new start of spiritual evolution, whereas Marian apparitions suggest that human beings could bypass pre-heaven stages by living a spiritually harmonious terrestrial life.

A perception of other dimensions is comparable to the limited and faulty world perception of a newborn child. It should be weighed against the information revealed by representatives of transcendental reality, such as Mother Mary. NDEs present evidence for the existence of a non-physical component in union with the brain and may offer indirect evidence of discarnate existence rather than proof of it [58]. After all, finding an organ for flying indicates that an organism is capable of some degree of air travel. Likewise, NDEs may be indirect evidence of survival after physical extinction. The Earth-like zones narrated by those who have had NDEs are comparable to the surroundings described by the Brazilian medium, Chico Xavier, in his Nosso Lar-a celestial rehabilitation center or a higher plane in the Catholic concept of purgatory [59]. Pre-death visions and SDEs may offer less complex evidence of discarnate existence. The percipients of death-related disclosures and Marian apparitions may be experiencing merely a glimmering of eternity, but they provide each other with complementary and confirmatory information. Research into NDEs has belied its early promise [60]. It would be a deception of the public on the part of survival researchers to tender an ultra-optimistic picture of postmortem existence in their publications without incorporating the information about after-death existence obtained through Marian apparitions. Furthermore, parapsychology is mind-centered, and mysticism is essentially God-centered. Parapsychology's research results are bound to be restricted about survival. We need guidance from the mystics for a fuller appreciation of life after death. The likelihood that Marian apparitional experiences are authentic 
has been demonstrated by scientific investigation [33,34]. If we supplement the categories of evidence itemized by survival researchers with the evidence of Marian apparitions in recent centuries, we have a corpus of compelling reasons to support those who are proponents of a belief in universal and eternal discarnate survival. The proof of after-death existence means that the whole is greater than the sum of its parts-non-reductionism.

From a scientific perspective, the debate on apparitions becomes meaningless if a conviction regarding higher consciousness is unsubstantiated, so it is apposite to revisit current theories relating to this subject. The prevailing neurobiological model of the mind is incapable of encompassing mysticism of a higher order. For studies of consciousness to progress, we need a working hypothesis of the mind and consciousness that would accommodate all the evidence in favor of mysticism, afterlife existences, and unique human subjective experiences, allowing for continued investigation and leaving the door open to further knowledge. Studies of mysticism signify the irreducibility of the mind and may show the way beyond the quantum consciousness, unravelling its near-paranormal nature. The human mind should be presumed to include a highly sophisticated receiver and a similar transmitter of messages.

Marian apparitions link science with religion. Marian apparitions also offer foolproof evidence for post-mortem survival and are highly relevant to the inner psychological and spiritual life. The best proof for the existence of a spiritual consciousness coexisting with our brain is discarnate survival, proving that a part of us can survive physical extinction and could exist independent of the brain. Marian apparitions offer an immense contribution to self-realization and God-realization, two driving forces inspiring human spiritual evolution. The events that led to the emergence of the spring at Lourdes on February 25, 1858 are well documented. The absence of unusual ESP powers on the part of Bernadette Soubirous, the percipient, and her reluctance to drink the muddy water emanating from the new spring and eat the grass-though asked to do so by the apparition-rule out an alternate paranormal explanation that might otherwise be postulated and would have involved the percipient's own clairvoyant detection of the spring. Moreover, all of the following point to a true Marian apparition at Lourdes: strong motivation on the part of the apparition, quasiphysical features of the apparition, integration of the apparition with the natural environment, utmost loyalty and obedience by the percipient to the image she saw, and controlled psychokinetic type manifestations. A manifestation of promised visible signs is awaited on the rocky hills of Medjugorje and among the pines of Garabandal.

\section{References}

1. Raymond M (1999) The last laugh: A new philosophy of near-death experiences, apparitions and the paranormal. Hampton Roads, Virginia, USA.

2. Raymond M, Perry P (2010) Glimpses of eternity. Guideposts, New York, USA.

3. Morse ML, Perry P (1990) Closer to the light. Villard Books, New York, USA

4. Craig LR (2000) A comparison of other world perceptions by near death experiencers and by the marian visionaries of medjugorje. Journal of Near-Death Studies 19(1): 45-52.

5. Craig LR (2001) Prophetic revelations in near-death experiences. Journal of Near-Death Studies 19(4): 233-239.

6. Bruce G (1985) A typology of near-death experiences. Am J Psychiatry 142(8): 967-969.

7. Craig LR, Arvin GR (2000) Near-death studies and modern physics. Journal of Near-Death Studies 18(3): 143-179.

8. Craig LR, Widdison HA (1997) The eternal journey: How near-death experiences illuminate our earthly lives. Warner Books, New York, USA.

9. Karles O, Erlender H (1977) At the hour of death. Avon books, New York, USA.

10. Callanan M, Kelly P (1992) Final gifts: understanding the special awareness, needs, and communications of the dying. Poseidon Press, New York, USA.

11. Kenneth R (1984) Heading toward omega: In search of the meaning of near-death experience. William Marrow, New York, USA.

12. Peter F, Elizabeth F (1995) The truth in the light: An investigation over 300 near-death experiences. Headline Books, London, UK.

13. Wallace A (1956) Stress and rapid personality changes. Int Rec Med Gen Pract Clin 169(12): p. 761-774

14. Pandarakalam JP (2017) A deeper understanding of consciousness through the study of creativity. Journal of Neuroquantology 15(2):171185.

15. Walter ST (1960) The teachings of the mystics. The New American Library, New York, USA.

16.John WP (2005) The far side of madness. Spring Publications, Washington, USA.

17. Joseph C (1981) The mythic image. The Princeton University Press, New Jersey, USA.

18. Goswami A (2014) The quantum creativity. Hay House, London, UK.

19. Osis K (1980) Apparitions: A new model. In: Roll W, Beloff J (Eds.), Research in Parapsychology, The Scarecrow Press, London, UK, pp. 1-2.

20. Michael T (2017) Do spirits wear clothes? the search light. The Academy for Spiritual and Consciousness Studies Inc, 26(5:15).

21. David F (2009) Life beyond death. Watkins Publishing, London, UK.

22. Rene L, Henri (1987) Scientific and medical studies on the apparitions at Medjugorje. Mount Salus Press, Dublin, Ireland.

23. Pandarakalam JP (2015) Auditory hallucinations; is the source of auditory hallucinations beyond the material brain? Paranormal Review Summer 75: 22-25.

24.Pandarakalam JP (2011) "Medjugorje apparitional occurrences: A parapsychological and spiritual analysis". Journal of Spirituality and paranormal Studies 34 (2): 100-117.

25. Bubalo J (1987) A thousand encounters with the blessed virgin mary in medjugorje. Friends of Medjugorje. Illinois, USA.

26. Connell J (1990) Queen of the cosmos. Paraclete Press, Orleans, USA.

27. Monroe A (1985) Travels outside the body. Broadway books, New York, USA.

28. Monroe A (1994) Ultimate journey. Broadway Books, New York, USA.

29. Nicky (2002) Get us out of here. Grafotisak, Grude, Europe.

30. Brown HM (1992) The final Hour. Faith Publishing Company, Ohio, USA.

31. Philip B (1986) Proclaim her name. AMI Press, Washington, USA.

32. Maria GJV (1994) Garabandal pines will enlighten the world. Rondas, Barcelona, Spain. 
33. Pandarakalam JP (2001) Are the apparitions of medjugorje real? Journal of Scientific Exploration, 15(2): 229-239.

34. Pandarakalam JP (2006) Certain parapsychological aspects of the visionary experiences of medjugorje. Paranormal Review, 38: 14-21.

35. Kondor SVD (1972) Fatima in lucia's own words. The Postulation Centre, Fatima, Portugal.

36. Carlos E (1994) An interview with sr. lucy st anne' oratory. Fatima, Portugal.

37. Alfred J (2005) The invisible bodies. Trafford Publishing, Victoria BC, Canada.

38. Ilibagiza I (2008) Our lady of kibeho. Hay House, Carlsbad, California.

39. Ilibagiza I, Erwin Steve (2011) The boy who met Jesus. Hay House, Carlsbad, California.

40. Pandarakalam JP (2007) Garabandal apparitional occurrences. Royal College of Psychiatrists Spirituality, Spain.

41. David F (2005) Is there an afterlife? a comprehensive overview of the evidence. London, UK.

42. Michael C (2002) Discovery of the secret of La Salette. Fayard Publications, Paris, UK.

43. Kenneth R (1980) Life at death: a scientific investigation of the neardeath experience. Coward-McCann, New York, USA.

44. Alfred AS (1996) Near-death prophecies of disaster and the new age: Are they true? Journal of Near-Death Studies Volume 14(3): 159-177.

45. Klimek DM (2018) Medjugorje and the supernatural. Oxford University Press, New York, USA.

46. Betty Stafford (2011) The afterlife unveiled: what the dead are telling us about their world. O-Books, Dublin, Ireland.
47. Rajiv P, Paul P (2016) Dying to wake up. Atria Books, New York, USA.

48. Schwartz G (2003) After life experiments. Atria Books, New York, USA.

49. Stevenson I (1997) Reincarnation and Biology. Praeger Publishers, Westport, USA.

50. Edward K, Williams KE, Adam C, Alan G, Michael G, et al. (2007) The irreducible mind: Toward a psychology for the $21^{\text {st }}$ century. Rowman\& Littlefield Inc, Lanham, USA.

51. Robert KD (2000) Modern physics and subtle realms: not mutually exclusive. Journal of scientific exploration 14(2): 275-279.

52. Ronald BA (2000) What can elementary particles tell us about the world in which we live? Journal of scientific exploration 14(2): 257-274.

53. Smythies JR (1988) Minds and higher dimensions. Journal of the Society for Psychical Research 55(81).

54. Paul JP (2018) Physicians involved assisted suicide. BJMP 11(1): a1102.

55. Andrew C (2010) Doctors' religious beliefs influence their views on end of life care BMJ 341: c4732.

56. (2014) Royal college of general parishioners assisted dying consultation analysis.

57. Pandarakalam JP (2011) A Search for the truth of near-death experiences. royal college of psychiatrist's spirituality.

58. Pandarakalam JP (1990) The Enigma of Near-Death Experiences. South Indian Journal of Psychiatry 13 (1): 131-136

59. Chico X (2006) Nosso lar. International Spirist Council, Brazil.

60. Kantenbaum R (1993) Transforming with the light. Journal of NearDeath Studies 12(1).

For possible submissions Click below: 